$621.833: 539.431: 539.4 .019 .1$

\title{
Influence of Impact Load on Fatigue Bending Strength of Case-Hardened Gears*
}

\author{
By Toshio Arda**, Hiroshige Fujio***, \\ Mikio Nishikawa****, and Ryuji Higashit
}

In this paper, the authors investigated the relationship between case-hardening condition and the bending fatigue strength of gear tooth under impact load.

The results obtained from this experiment are summarised as follows:

(1) There exists an optimal thickness of case-hardened layer for bending endurance limit of case-hardened gears, but it differs from an optimal thickness of case-hardened layer for im. pact bending strength. And an excessively large thickness of case-hardened layer causes an decrement of impact bending strength.

(2) When impact load $P$ is less than $0.63 P_{i m}{ }^{\prime}\left(P_{i m}^{\prime}\right.$ : impact fracture load), and impact velocity is below $5 \mathrm{~m} / \mathrm{sec}$ such as in this experiment, impact load has no influence on fatigue strength.

(3) Few times applications of an impact load, which is nearly equal to endurance limit load, cause an increment of bending endurance limit.

\section{Introduction}

It is an important problem from the view point of preventing tooth fracture to investigate how large impact loads such as induced at the start or on the way of driving gear apparatus, influence the endurance limit of gears, but few investigations have been performed. In this paper, the relationship between case-hardening condition and bending fatigue strength of gear tooth under some impact load application was investigated with case. hardened gears having higher surface endurance limit than bending endurance limit.

\section{Nomenclature}

$W_{1}$ : dead weight $\mathrm{kg}$

$W_{2}$ : weight of impact load transmission bar $\mathrm{kg}$

$h$ : height of dead weight $\mathrm{m}$

$v_{1}$ : velocity of dead weight just before impact of dead weight and impact load transmission bar $\mathrm{m} / \mathrm{sec}$

$v_{2} \quad$ : velocity of dead weight and impact load transmission bar just after impacting each other $\mathrm{m} / \mathrm{sec}$

* Received Ist August, 1970.

** Professor, Faculty of Engineering, Kyoto University, Sakyo-ku, Kyoto.

*** Assistant, Faculty of Engineering, Kyoto University.

***** Engineer, Teijin Co., Ltd.

it Engineer, Dainihon Printing Co., Ltd. $\sigma_{\text {upim }}:$ endurance fatigue limit in case of applying one impact load before fatigue test $\mathrm{kg} / \mathrm{mm}^{2}$

$\sigma_{u p}:$ endurance fatigue limit without impact load application $\mathrm{kg} / \mathrm{mm}^{2}$

$P_{i m}$ : impact load $\mathrm{kg}$

$P_{i m}{ }^{\prime}$ : impact fracture load $\mathrm{kg}$

$P_{i m 0}$ : maximum impact load for $\sigma_{u p i m} / \sigma_{u p}=1 \mathrm{~kg}$

$N_{i m}$ : number of load cycles in case of applying one impact load

$N_{o}$ : number of load cycles without impact load application

\section{Experimental procedure}

\section{$3 \cdot 1$ Test gear}

Test gears have the following dimensions: module $m=4$, pressure angle $\alpha=20^{\circ}$, number of teeth $z=18$, face width $b=10 \mathrm{~mm}$

Material and heat -treatment conditions of test gears are shown in Table 1.

Table 1 Gear material and heat-treatment condition

\begin{tabular}{|c|c|c|c|c|}
\hline Test gear designations & A & B & $\mathrm{C}$ & $\mathrm{D}$ \\
\hline Material & \multicolumn{4}{|c|}{ SCM21 } \\
\hline Carburizing method & \multicolumn{4}{|c|}{ Gas carburized } \\
\hline Carburizing temperature ${ }^{\circ} \mathrm{C}$ & \multicolumn{4}{|c|}{930} \\
\hline Carburizing time hour & $5 / 6$ & $11 / 2$ & \multicolumn{2}{|c|}{ 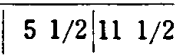 } \\
\hline Hardening temperature ${ }^{\circ} \mathrm{C}$ & \multicolumn{4}{|c|}{850} \\
\hline
\end{tabular}


Before case-hardening operations, the side faces of test gears were plated with copper to prevent the side faces from carburizing.

\subsection{Impact test and bending fatigue test}

In Fig. 1 is shown the outline of the impact test attachment and measuring apparatuses of strain at the tooth fillet. A test gear is fixed at the gear holder by a shaft and two teeth. The dead weight, which is held up to the appointed height with a direct current magnet, falls down when the circuit is broken, and an impact load works on a tooth of test gear through the impacting load transmission bar.

The strain at the tooth fillet of compression side is measured with a wire strain gauge. Impact load is also examined with a load-cell set up in. stead of a gear holder.

Bending fatigue tests are performed by using a bending fatigue testing machine (pulsator) which has been developed in our laboratory (1). The testing machine consists of a fuel injection pump, a

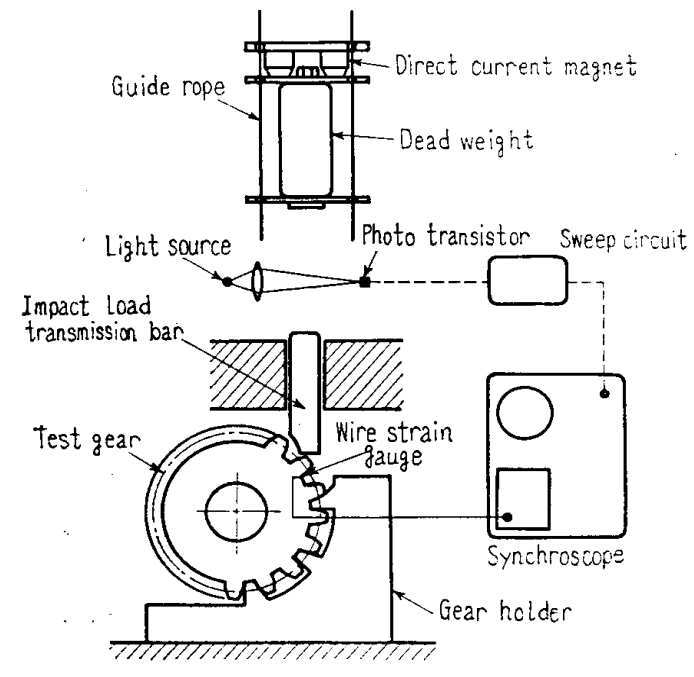

Fig. 1 Impact test attachment

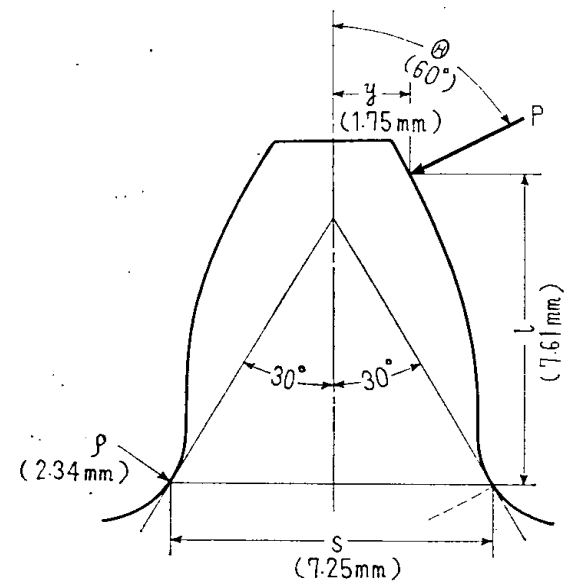

Fig. 2 Loading position and tooth dimensions pressure indicator, a pressure cylinder and a piston. The frequency of load repetition in fatigue test was held to about $650 \mathrm{c} / \mathrm{min}$.

In a bending fatigue test and an impact test, the position and direction of load application to a tooth of test gear was set as shown in Fig. 2 .

\subsection{Measurement of hardness distribution} of test gears

The side of gear tooth was ground by about $2 \mathrm{~mm}$ and finished with emery paper. Hardness measurement was done on this face by a MicroVickers hardness tester. Hardness was measured on the line of this face passing through the intersecting point of the tooth fillet curve with Hofer's critical section and normal to the fillet curve.

3.4 Measurement of plastic deformation of a tooth due to impact loading

Plastic deformation of a tooth of test gears due to impact loading was measured with a gear tooth micrometer, holding its jaw in symmetrical position over 3 teeth of test gears.

\section{Test results}

4.1 Hardness distribution of test gear tooth Figure 3 shows hardness distribution of test gear tooth at the tooth fillet. And, Fig. 4 shows

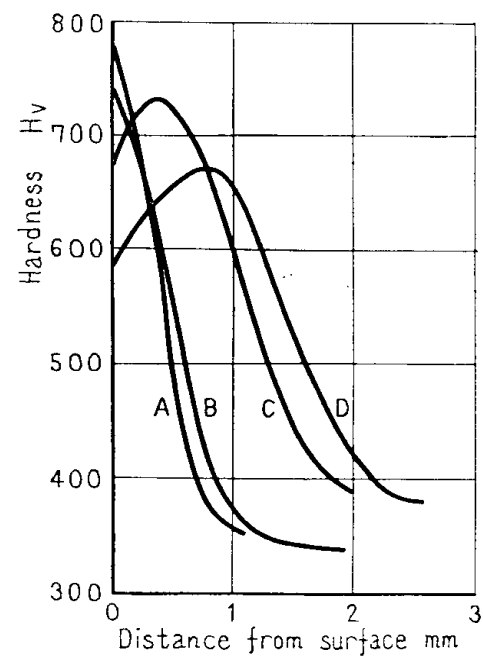

Fig. 3 Hardness distribution at tooth fillet

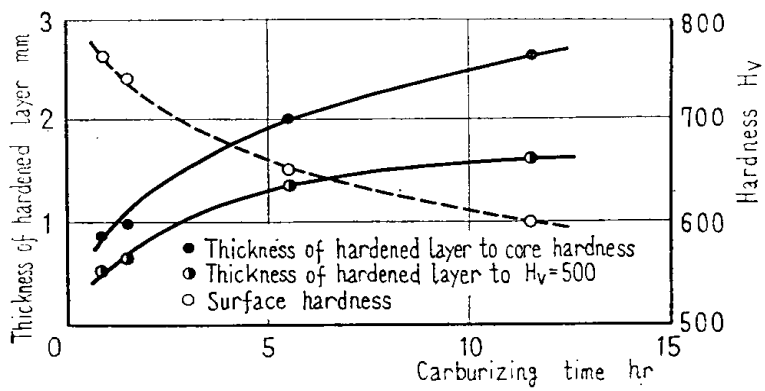

Fig. 4 Relation between carburizing time and thickness of hardened layer, or surface hardness 
the relation among carburizing time, hardness and thickness of hardened layer.

The thickness of hardened layer is denoted by the distance from the surface to the point where hardness becomes equal to $H_{v} 500 . H_{V} 500$ corresponds nearly to $R c 50$ and this is usually taken as a standard in the determination of thickness of hardened layer. The thickness of hardened layer increases unproportionally with carburizing time, but an excessively large hardened layer causes a decrement in the surface hardness. The reason is conjectured as follows. Carbon density near surface layer increases with carburizing time, therefore in the case of quenching, start point and finish point of martensite transformation go down. Con-

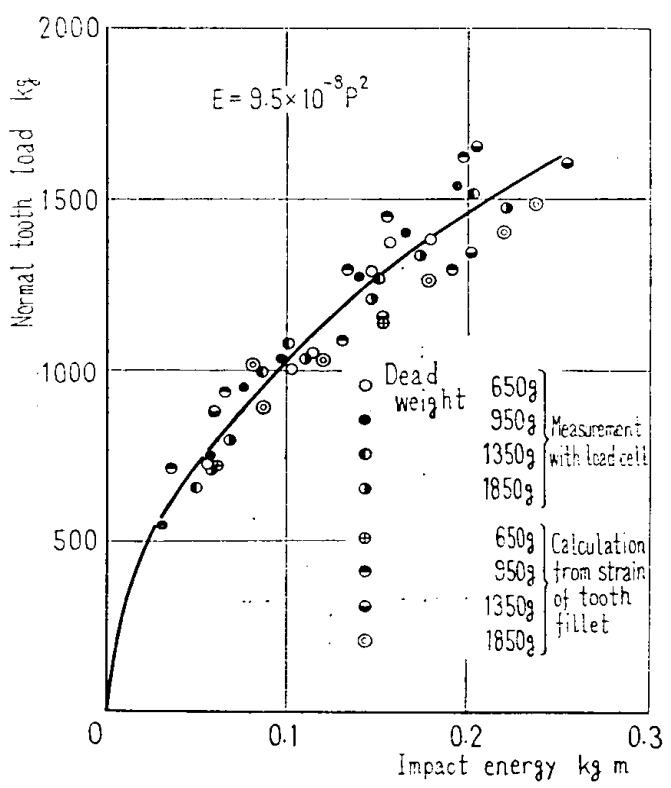

Fig. 5 Relation between normal tooth load and impact energy

Gear B

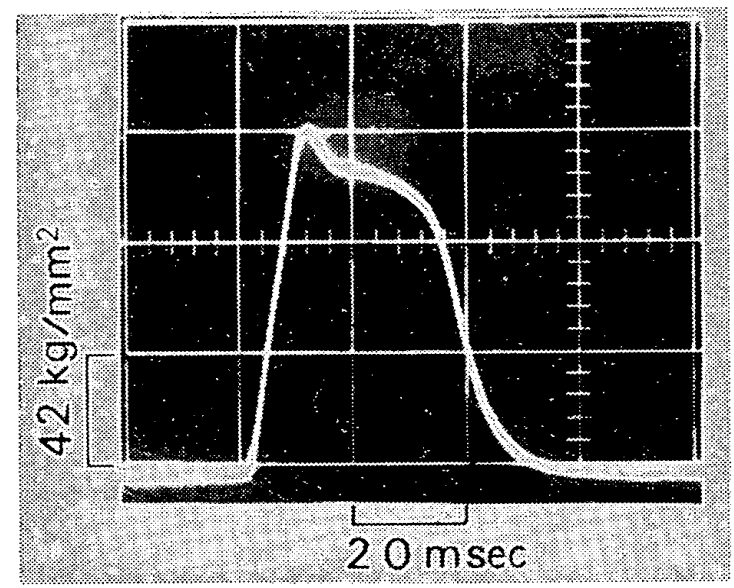

By pulsator test (Normal tooth load $1000 \mathrm{~kg}$ ) sequently a greater part of austenite structure which is stable at high temperature is retained, and the hardness of hardened layer decreases.

4.2 Relation among impact load, bending load and stress at tooth fillet

Impact energy is calculated from impact load. Assuming that velocities of dead weight and im. pacting load transmission bar immediately after impacting each other are approximately equal, we obtain

$$
v_{2}=W_{1} v_{1} /\left(W_{1}+W_{2}\right)
$$

Impacting velocity is shown as follows

$$
v_{1}=\sqrt{2 g h}
$$

where $g$ is acceleration of gravity. Using Eq. (2), impact energy which gear tooth absorbs is then obtained as follows:

$$
E=\left(W_{1}+W_{2}\right) v_{2}^{2} /(2 g)=W_{1}{ }^{2} h /\left(W_{1}+W_{2}\right) \cdots(3)
$$

Figure 5 shows the relation among the impact energy by Eq. ( 3 ), the load calculated by true stress calculating equation ${ }^{(2)}$ on the tooth fillet and the load measured with a load-cell set up instead of a gear holder. It is evident that within the experimental scattering of the data, there exists a fixed relation between impact energy $E$ and impact load. The loads calculated with a wire-strain gauge at the tooth fillet scatter compared with the loads measured with a load-cell, but the principal reason for the scattering is some deviation of wire-strain gauge position.

Assuming that impact energy is proportional to the square of normal tooth load, then

$$
E=c P^{2}
$$

where $c$ is constant.

From Fig. $5, c$ corresponds to $9.5 \times 10^{-8} \mathrm{~m} / \mathrm{kg}$

$$
E=9.5 \times 10^{-8} P^{2} \quad \ldots \ldots \ldots \ldots \ldots \ldots \ldots \ldots \ldots \ldots(5)
$$

The relation is plotted with a full line in Fig. 5.

\section{Gear B}

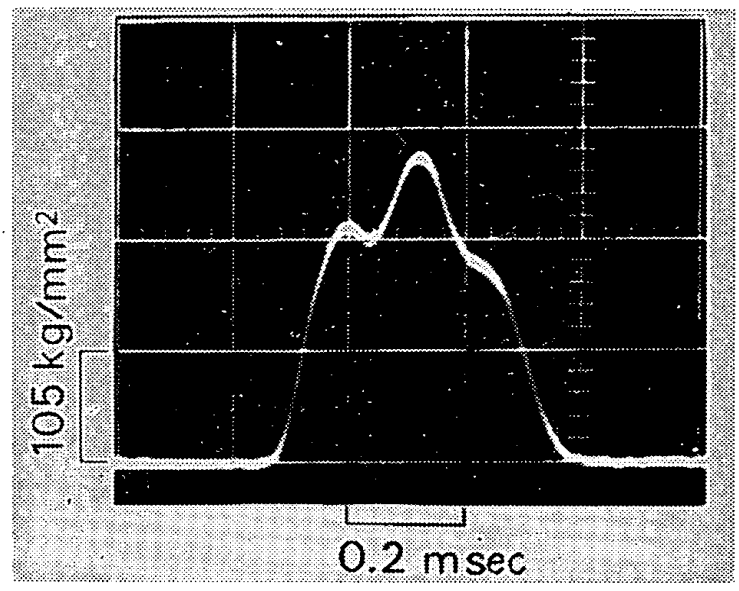

By impact test (Impact load $1660 \mathrm{~kg}$ )

Fig. 6 Stress wave forms measured at compression side of tooth fillet 


\subsection{Results obtained from bending strength} test.

Figure 6 shows stress wave forms at the tooth fillet in cases of bending fatigue test and impact test. The operation time of impact load is a mere one hundredth that of pulsator test.

Figure 7 shows load-deflection curves in static bending test. The tooth deflection under the same load decreases with carburizing time. But the deflection given by those curves is not that of a gear tooth accurately, which includes, though very small, the deflection of the two teeth of the gear holder.

Figure 8 shows the relation between bending

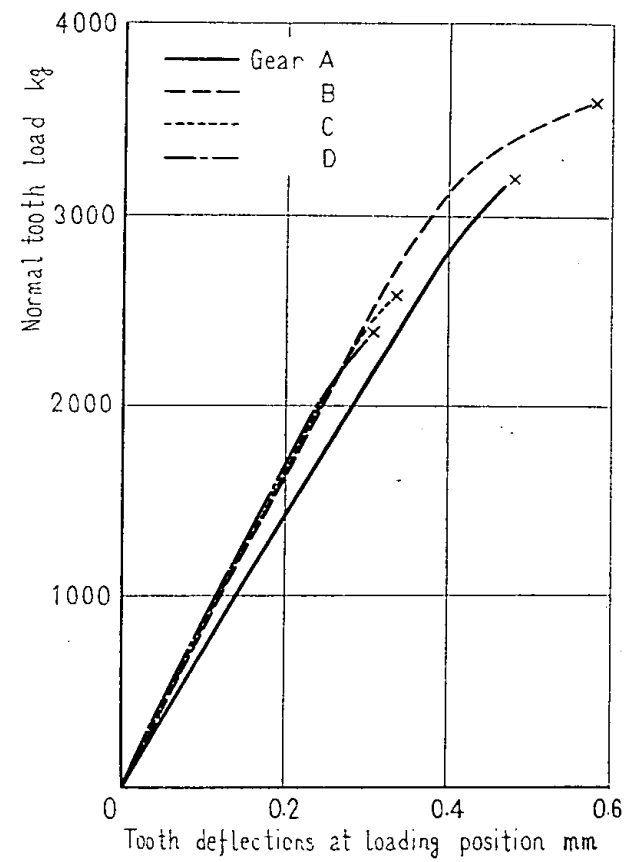

Fig. 7 Static loading test results

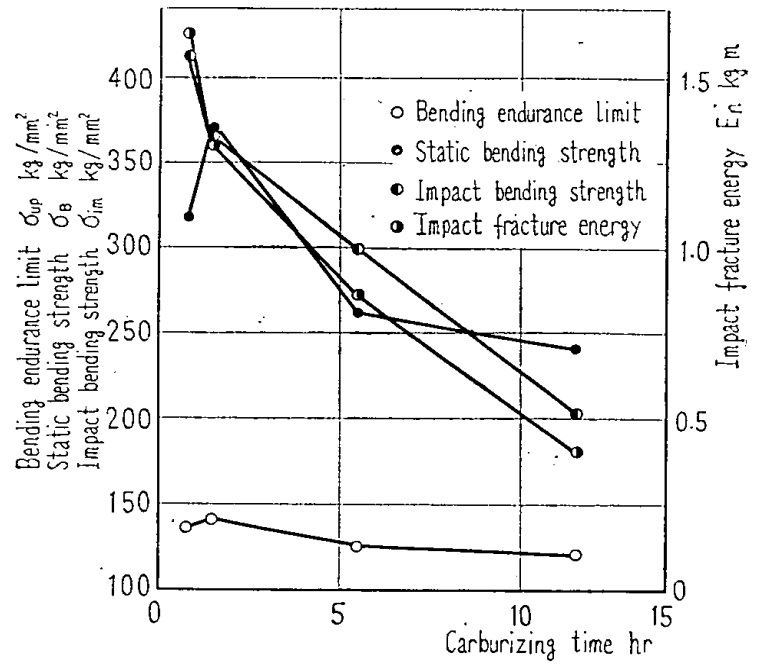

$\mathrm{F}^{1} \mathrm{~g} .8$ Relation between carburizing time and bending strength strength and carburizing time in static bending test, bending fatigue test and impact test.

As seen from these experimental results, the static bending strength and bending fatigue strength of gear B are largest, but those for other three kinds of gears decrease with carburizing time. Gear A has the largest impact strength and the impact strength decreases with carburizing time. These results depend on the difference of hardness of hardened layer, residual stress and brittleness of case-hardened layer.

\subsection{Impact test results}

Figure 9 shows the relation between impact en. ergy and increment of plastic deformation induced by impact application. Impact fracture energy is defined as the value of impact energy, when increment of plastic deformation changes steeply and impact bending strength is defined as the stress on

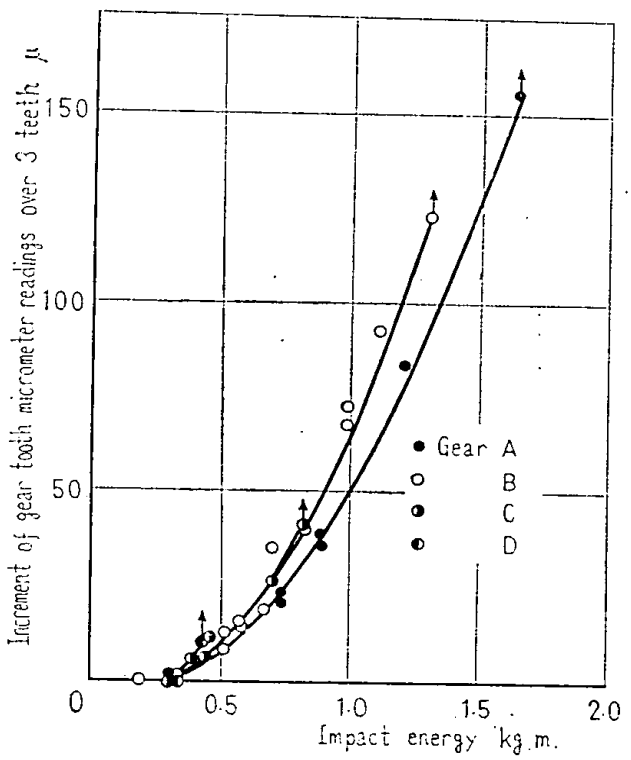

Fig. 9 Impact test results

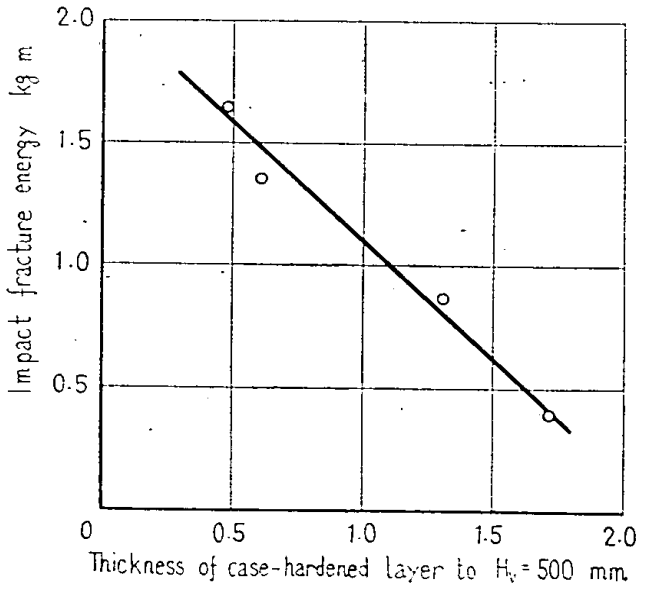

Fig. 10 Relation between thickness of case-hardened layer and impact fracture energy 
the tension side of tooth fillet in that period. They are shown in Fig. 8.

Figure 10 shows the relation between impact fracture energy and thickness of hardened layer (=distance from the surface to the point where hardness becomes equal to $H_{V}$ 500). Impact energy decreases proportionally with thickness of hardened layer. Maximum value of impact load, at which a visible deflection appears after application of impact load, is nearly constant independently of carburizing time. In this case, the true stress at the tension side of tooth fillet is nearly equal to $190 \mathrm{~kg} / \mathrm{mm}^{2}$ and impact energy $E$ is nearly equal to $0.34 \mathrm{~kg} \mathrm{~m}$. Plastic deformation of tooth by impact load increases with carburizing time for the same load. From Fig. 7 and Fig. 9 it is found that in case of normal tooth load over $1880 \mathrm{~kg}$, the rate of plastic deformation increases with carburizing time, consequently thickness of hardened layer.

4.5 Bending fatigue strength after application of impact load

After one impact load application by dead weight $W=1.5 \mathrm{~kg}$, a bending fatigue test was car-

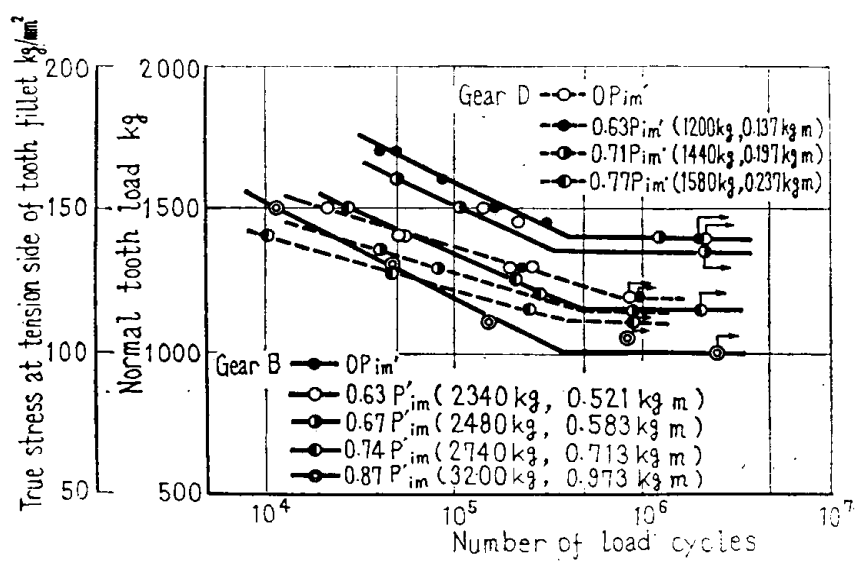

Fig. 11 Results of fatigue test after application of one impact load

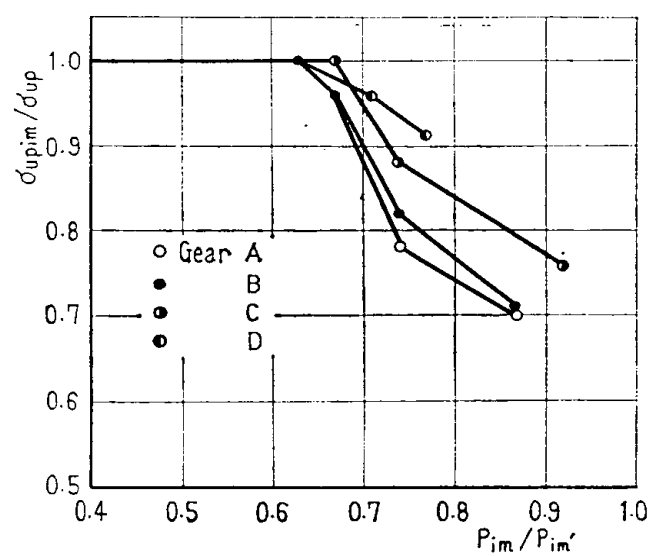

Fig. 12 Decrement grade of endurance limit due to impact preload ried out. The result is shown in Fig. 11. The $S-N$ curves for each gear shift down in parallel with $S-N$ curve, without impact preload. Namely, the gradient of $S-N$ curve, which shows the fatigue life portion, takes nearly constant values in case of impact load application. The bending endurance limits of gears B and D decrease with impact preload corresponding to about $70 \%$ of impact frac. ture load.

Figures 12, 13 and 14 show decrements of bending endurance limit due to impact load application. The relation between $\sigma_{u p i m} / \sigma_{u p}$ and $P_{i m} /$ $P_{i m}{ }^{\prime}$ is plotted in Fig. 12. The range for $\sigma_{u p i m} /$ $\sigma_{u p}=1$, in other words, the range where impact load has no influence on bending endurance limit, is constant for every test gear. Here $P_{i m}$ and $E$ are less than or equal to $0.63 P_{i m}{ }^{\prime}$ and $0.4 E_{i m}$ respectively. In case of impact load over this range $\sigma_{u p i m} / \sigma_{u p}$ decreases linearly. The grade of decrement increases with shorter carburizing time. The principal reason is not the decrement of impact load with shorter carburizing time, but the incre-

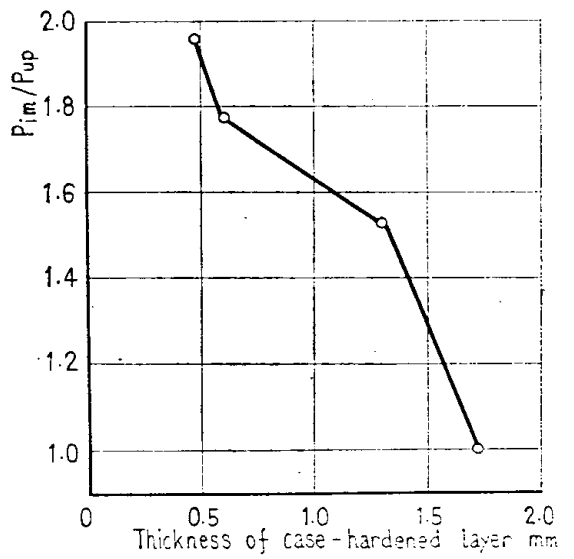

Fig. 13 Relation between thickness of case-hardened layer and maximum value of $P_{l m} / P_{u p}$, when $\sigma_{u p ! m}$ is equal to $\sigma_{u p}$

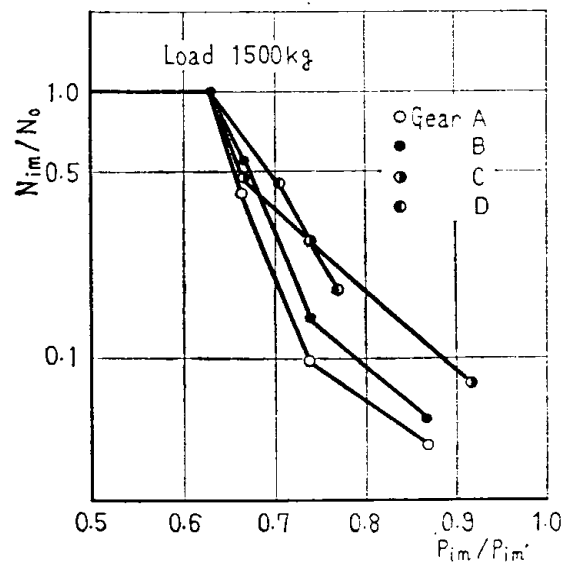

Fig. 14 Decrement grade of fatigue life strength due to impact preload 
ment of the absolute value of $P_{i m}$ with shorter carburizing time, even in a case where $P_{i m} / P_{i m}$ ' has same value.

Figure 13 shows the relation between thickness of case-hardened layer and $P_{i m 0} / P_{u p}$ in the range where impact load has not any influences on bending endurance limit. $P_{i m 0} / P_{u p}$ in the range above shown increases with decrement of thickness of case-hardened layer. From this result it is found that influence of impact load on endurance limit increases with thickness of case-hardened layer.

Figure 14 shows the relation between $P_{i m} / P_{i m}{ }^{\prime}$ and $N_{i m} / N_{0}$. Regarding the fatigue life strength, the same tendency could be observed as in case of endurance limit.

\subsection{Influence of impact velocity}

Influence of impact load velocity on bending endurance limit is shown in Fig. 15. Also, $S-N$ curves, when the static load of the same value as impact load is applied by a universal testing machine, are shown in Fig. 15. As seen in this figure, the range of the impact load velocity ( 2 $4 \mathrm{~m} / \mathrm{sec}$ ) has hardly any influence on bending endurance limit and on the decrement grade of fatigue life portion. In case of static load application compared to case of impact load application, the decrement grade of bending endurance limit does not change and that of fatigue life strength increases to some extent.

4.7 Influence of one application of impact load in the course of bending fatigue test

Influence of one application of impact load in the course of bending fatigue test on bending endurance limit is shown in Fig. 16. Then impact load and impact energy are $0.71 P_{i m}{ }^{\prime}$ and a half of impact fracture energy respectively. $S-N$ curve in case of one impact load application to $N=10^{4}$ in the course of bending fatigue test, coincides with that in case of one impact load application

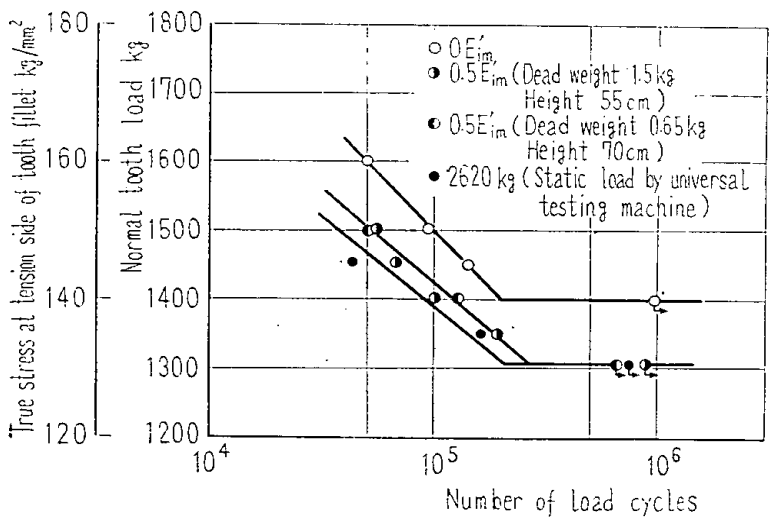

Fig. $15 S-N$ curves in case of changing impact velocity (Gear B) at $N=0$. Also, bending endurance limit in case of impact load application at $N=5 \times 10^{4}$, coincides with those at $N=0$ or $10^{4}$, but a little increment of fatigue life strength at $N=5 \times 10^{4}$ is recognized.

4.8 In case of plural times applications of impact load in the course of bending fatigue test

Influence of $5 \sim 100$ times applications of impact load in the course of bending fatigue test on bending endurance limit of gear $B$ is shown in Fig. 17. The plural times applications of impact load with $0.32 P_{i m}{ }^{\prime}\left(0.1 E_{i m}{ }^{\prime}\right)$ has no influence on bending endurance limit. The five times applications of impact load with $0.39 P_{i m}{ }^{\prime}\left(0.15 E_{i m}{ }^{\prime}\right)$ causes some increment of bending endurance limit and fatigue life strength. The ten times applications of impact load causes an increment of fatigue life strength, but no increment of bending endurance limit. In case of $10 \sim 40$ times applica-

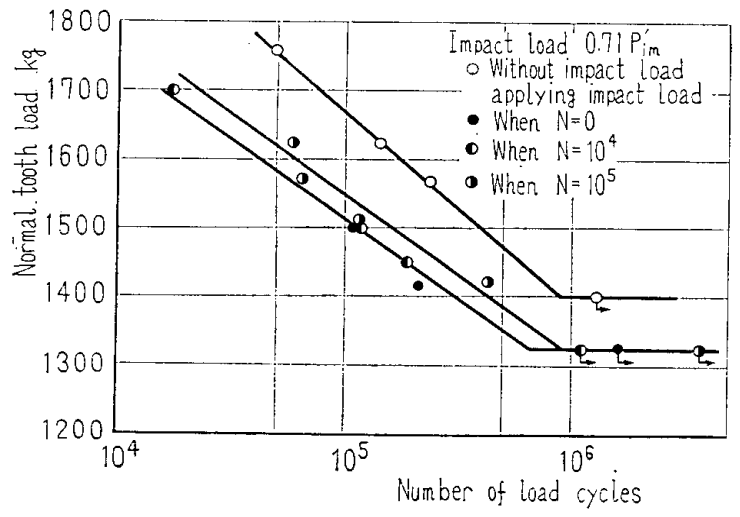

Fig. $16 S-N$ curves in case of applying impact load in the course of fatigue test (Gear B)
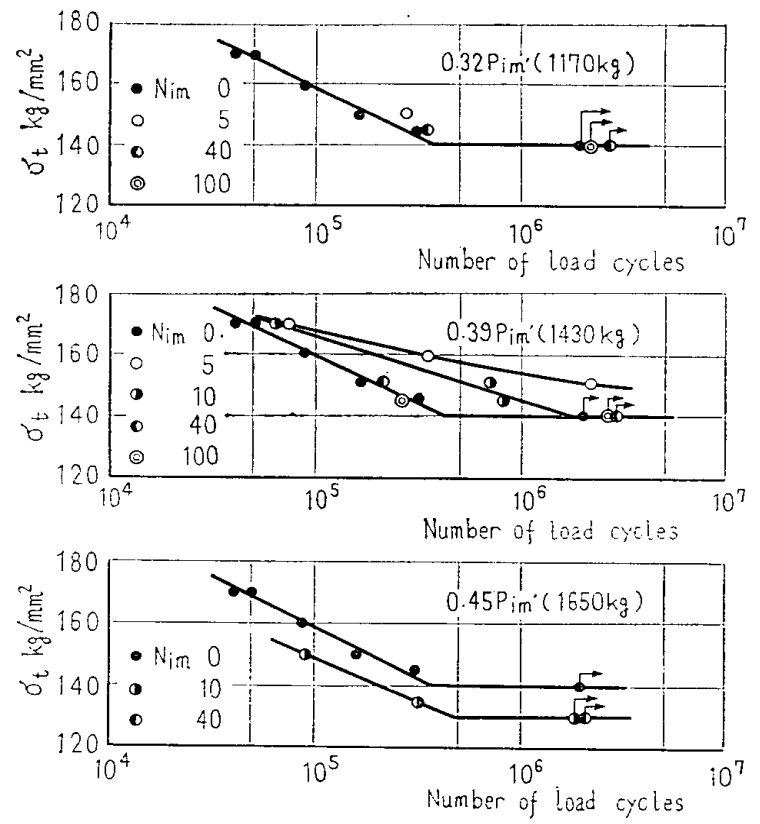

Fig. $17 S-N$ curves in case of applying plural times of impact load before tatigue test 


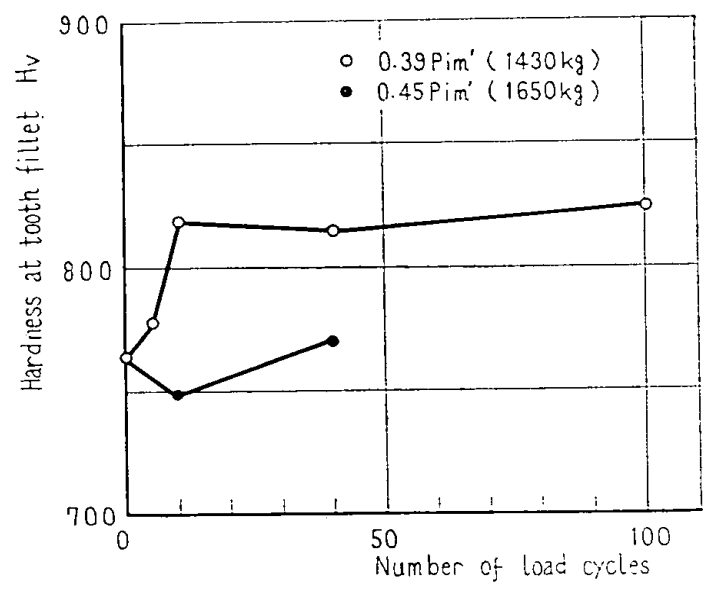

Fig. 18 Hardness change due to impact loading

tions of impact load with $0.45 P_{i m}{ }^{\prime}\left(0.2 E_{i m}{ }^{\prime}\right), S-N$ curve shifts down compared to the $S-N$ curve without impact load, and the decrement grade of bending endurance limit is $7 \%$.

The change of hardness at the tooth fillet was measured to investigate the reason why $5 \sim 10$ times applications of impact load $\left(0.39 P_{i m}{ }^{\prime}\right)$ caused an increment of bending endurance limit and fatigue life strength (Fig. 18). But, as it was impossible to measure the hardness on the surface of tooth fillet, the hardness was measured at the point $10 \mu$ inner from the surface of tooth fillet at the tension side. The hardness increment due to workhardening effect induced by impact load $0.39 P_{i m}{ }^{\prime}$ was observed clearly. The impact load $0.39 P_{i m}{ }^{\prime}$ corresponds to normal tooth load $1430 \mathrm{~kg}$. As this load is a little higher than bending endurance limit load, damage of the tooth fillet due to $5 \sim 10$ times applications of impact load is considered to be very little. So, the authors may conclude that the increment of bending endurance limit mainly comes from the change of the strength at the tooth fillet due to increment of hardness. Any increment of hardness due to work-hardening in case of impact load $0.45 P_{i m}{ }^{\prime}$ is not observed. Impact load $0.45 P_{i m}{ }^{\prime}$ corresponds to normal tooth load $1650 \mathrm{~kg}$. This load is considerably higher than bending endurance limit of gear B. therefore, in this case, a comparatively few load applications such as $10 \sim 40$ times causes a decrement. of bending endurance limit.

\section{Conclusions}

The main results obtained from this investigation are summarised as follows.

(1) For case-hardened gear, there exists an optimal thickness of hardened layer to bending endurance limit. But, this thickness does not coincide with an optimal thickness of hardened layer to impact load. Within the range of carburizing time in this test, strength for impact load increases with decrement of thickness of case-hardened layer.

(2) In the range of impact load ratio $P_{i m} /$ $P_{i m}{ }^{\prime} \leqq 0.63$, the impact load has no influence on bending endurance limit.

(3) $P_{i m} / P_{u p}$, ratio of impact load which has no influence on bending endurance limit, increases with shorter carburizing time.

(4) In the range of impact velocity in this test, impact velocity has practically no influence on bending endurance limit.

(5) Influences of impact load application to $N=10^{4}$ in bending fatigue test on bending endurance limit are of the same extent as those at $N$ $=0$.

(6) There exist increments of bending endurance limit in case of plural times applications of impact load approximately equal to endurance limit load.

(7) In this impact test, the operation time of impact load is about $0.5 \mathrm{msec}$. This time is approximately equal to the period of meshing frequency of gears $3000 \mathrm{~Hz}$ in case of contact ratio 1.5. In other words, this meshing frequency corresponds to that of gear with 18 teeth driven by $10000 \mathrm{rpm}$. Bending endurance limit in case of impact load application within range of impact load in this test shows no difference with endurance limit by pulsator test. Therefore, considering the influence of dynamic load, the bending strength results obtained by low speed gearing could be applied to high speed gearing driven by about $10000 \mathrm{rpm}$.

\section{References}

(1) Aida, T., et al., Trans. Japan Soc. Mech. Engrs. (in Japanese), Vol. 34, No. 264 (1968-8), p. 1479.

(2) Aida, T. and Terauchi, Y., Trans. Japan Soc. Mech. Engrs. (in Japanese), Vol. 27, No. 178 (1961-6), p.853. 